\title{
CFD Modelling of a Two-Phase Closed Thermosyphon Charged with R134a and R404a
}

\author{
Bandar Fadhl $^{a,+}$, Luiz C. Wrobel ${ }^{a^{*}}$, Hussam Jouhara $^{b}$ \\ ${ }^{a}$ Institute of Materials and Manufacturing \\ ${ }^{b}$ Institute of Energy Futures, RCUK Centre for Sustainable Energy Use in Food Chains (CSEF) \\ ${ }^{a, b}$ College of Engineering, Design and Physical Sciences, Brunel University London, Uxbridge, \\ Middlesex UB8 3PH, London, UK
}

Keywords: Two-phase thermosyphon, Computational fluid dynamics (CFD), Phase change material, Pool boiling, Liquid film condensation, R134a, R404a

\section{A B S T R A C T}

This paper examines the application of CFD modelling to simulate the two-phase heat transfer mechanisms in a wickless heat pipe, also called a thermosyphon. Two refrigerants, R134a and R404a, were selected as the working fluids of the investigated thermosyphon. A CFD model was built to simulate the details of the two-phase flow and heat transfer phenomena during the start-up and steady-state operation of the thermosyphon. The CFD simulation results were compared with experimental measurements, with good agreement obtained between predicted temperature profiles and experimental temperature data, thus confirming that the CFD model was successful in reproducing the heat and mass transfer processes in the R134a and R404a charged thermosyphon, including the pool boiling in the evaporator section and the liquid film in the condenser section.

\footnotetext{
${ }^{+}$Permanent address: Department of Mechanical Engineering, Umm Al-Qura University, Makkah, KSA

* Corresponding author. Tel.: +441895266696. E-mail address: luiz.wrobel@brunel.ac.uk
} 


\section{INTRODUCTION}

A wickless heat pipe is a two-phase heat transfer device with a highly effective thermal conductivity, containing a small amount of working fluid that circulates in a sealed tube utilising the gravity forces to return the condensate back to the evaporator [1]. When the evaporator section is heated by an external source, the heat will be transferred to the working fluid through the evaporator wall. The working fluid absorbs an amount of heat proportional to the latent heat of evaporation, which is sufficient to change the fluid from liquid to vapour. The vapour then moves to the condenser section where it changes phase again, back to liquid, along the condenser's wall, giving up its latent heat that it absorbed in the evaporator section. The condensed liquid is then returned to the evaporator due to gravitational or capillary forces, according to the type of heat pipe [1-5]. Heat pipes have been successfully used for waste heat energy recovery in a vast range of engineering applications, such as heating, ventilation, and air conditioning (HVAC) systems [2], ground source heat pumps [6], water heating systems [7] and electronics thermal management [8].

The most important characteristics to consider in identifying suitable working fluids are compatibility and wettability with the heat pipe materials, good thermal stability and conductivity, high latent heat of evaporation, high surface tension and low viscosity for both liquid and vapour [9]. In typical thermosyphons, the selection of the working fluid and the shell materials is subject to the working environment and temperature under which the thermosyphon-based system will function. For low temperature applications, ammonia and various refrigerants such as R134a, R22 and R410a have been used as working fluids with copper, steel, aluminium and other compatible metals as shell materials. Water has been proven to be a suitable working fluid for temperatures between $30^{\circ} \mathrm{C}$ and $300^{\circ} \mathrm{C}$, with good compatibility with various metals including copper and stainless steel. Liquid metals and various organic fluids have been selected for thermosyphons when the working temperature is above $300^{\circ} \mathrm{C}$ $[6,10-14]$.

Two-phase closed thermosyphons have been extensively used in many applications [15]; however, only a limited number of CFD numerical simulation studies have been published. Kafeel and Turan [16] studied the effect of different pulsed increases in 
heat input at the evaporator zone on the behaviour of thermosyphons. They used similar thermosyphon configurations to that of Amatachaya et al [17] to validate the simulation model, and an Eulerian model to simulate film condensation at the condenser zone with a filling ratio of $30 \%$ of the evaporator zone. Alizadehdakhel et al. [18] reported on a two-dimensional model and experimental studies in which they investigated the effect of input heat flow and filling ratio of the working fluid on the performance of a two-phase closed thermosyphon, using water as the working fluid.

Zhang et al. [19] developed a two-dimensional model for a disk-shaped flat twophase thermosyphon used in electronics cooling. The authors simulated the flow inside the disk flat two-phase thermosyphon as a single-phase flow with water as the working fluid. They compared the distribution of vapour velocity and temperature with experimental results to determine the factors that affected the axial thermal resistance of a flat thermosyphon.

Annamalai and Ramalingam [20] carried out an experimental investigation and CFD analysis of a wicked heat pipe using ANSYS CFX. The authors considered the region inside the heat pipe as a single phase of vapour and the wick region as the liquid phase, and used distilled water as the working fluid. They compared the predicted surface temperature along the evaporator and condenser walls and the vapour temperature inside the heat pipe with the experimental data. Lin et al. [21] built a CFD model to predict the heat transfer capability of miniature oscillating heat pipes (MOHPs) using VOF and Mixture models, and water as the working fluid. The effects of different heat transfer lengths and inner diameters at different heat inputs were used to analyse the heat transfer capability of MOHPs.

There is an obvious gap in the published literature on CFD simulations of the twophase heat transfer/flow within a wickless heat pipe. Therefore, the purpose of this paper is to build a CFD model to cover all details of two-phase flow and heat transfer phenomena during the operation of a wickless heat pipe charged with two working fluids, namely R134a and R404a. The reported work focuses on their thermal performance during start-up and operation. The developed CFD model has been validated experimentally and theoretically with good agreement. A user-defined 
function (UDF), together with a VOF model, has been used in order to simulate the phase change during the pool boiling and the liquid film condensation.

\section{CFD SIMULATION OF MASS AND HEAT TRANSFER DURING THE EVAPORATION AND CONDENSATION PROCESSES}

In this study, the commercial code ANSYS FLUENT 14.0 and the Volume of Fluid (VOF) method have been applied for the modelling of a closed two-phase thermosyphon. The details of the VOF model and the Navier-Stokes equations for the VOF model, relevant to this study, have been discussed by Fadhl et al. [1].

During the thermosyphon operation, phase change occurs from liquid to vapour phase during the nucleate pool boiling in the evaporator section and from vapour to liquid phase during the liquid film condensation in the condenser section. In this study, userdefined functions (UDFs) are employed to specify customised source terms reported by Fadhl et al. [1] and De Schepper et al. [22] for the existing governing equations in the FLUENT package, in order to determine mass and energy sources for the phases involved in the mass and heat transfer processes.

Mass sources, $S_{M}$ in the volume fraction equation, can be given by the following expressions:

For mass transfer during the evaporation process:

$$
\begin{gathered}
S_{M_{1}}=-0.1 \rho_{L} \alpha_{L} \frac{T_{m i x}-T_{\text {sat }}}{T_{\text {sat }}} \\
S_{M_{2}}=-\left(S_{M_{1}}\right)
\end{gathered}
$$

For mass transfer during the condensation process:

$$
\begin{gathered}
S_{M_{3}}=0.1 \rho_{V} \alpha_{V} \frac{T_{\text {sat }}-T_{\text {mix }}}{T_{\text {sat }}} \\
S_{M_{4}}=-\left(S_{M_{3}}\right)
\end{gathered}
$$

where $T_{\text {mix }}$ and $T_{\text {sat }}$ are the mixture and saturation temperatures, respectively, and $\alpha_{L}$ and $\alpha_{V}$ are the volume fraction of the liquid and vapour phases, respectively. 
In the VOF model, the temperature is introduced as a mixture temperature rather than liquid or vapour temperatures, as the VOF model associates some variables such as temperature and velocity with the mixture phase, not with a specific phase. The volume fraction for each phase in the cell has been defined by the VOF model. Therefore, the evaporation process required two mass sources for the calculation of the mass transfer, Eq. (1) describing the amount of mass taken from the liquid phase and Eq. (2) describing the amount of mass added to the vapour phase. The same procedure takes place for the condensation process, Eq. (3) and Eq. (4) describing the amount of mass transfer from vapour to liquid phase.

Energy sources $S_{E}$ in the energy equation used in the present study are determined by multiplying the calculated mass sources in Eq. (1) and Eq. (3) by the latent heat of evaporation for the working fluid, and can be expressed as follows;

$$
\begin{aligned}
& S_{E_{1}}=\left(S_{M_{1}}\right) \cdot L H \\
& S_{E_{2}}=\left(S_{M_{3}}\right) \cdot L H
\end{aligned}
$$

where $L H$ is latent heat of evaporation. A single source term for both phases is required in the evaporation, Eq. (5) or condensation, Eq. (6) during the heat transfer process.

\section{MODEL GEOMETRY AND COMPUTATIONAL MESH}

A two-dimensional model was developed to simulate the two-phase flow and heat transfer phenomena in a thermosyphon. According to the experimental conditions described in [1], a closed thermosyphon tube wall made of copper with a thickness of $0.9 \mathrm{~mm}$ and a total length of $500 \mathrm{~mm}$ was used as the thermosyphon geometry, as can be seen in Figure 1. The evaporator and condenser sections of the thermosyphon model are taken to be $200 \mathrm{~mm}$ in length, making the adiabatic section $100 \mathrm{~mm}$ long. The outer and inner diameters are $22 \mathrm{~mm}$ and $20.2 \mathrm{~mm}$, respectively.

The temperature distribution along the thermosyphon wall was monitored using eight thermocouples, according to the experimental setup [1]. As shown in Figure 1, $\mathrm{T}_{\mathrm{a}}$ gave the temperature of the adiabatic section, $\mathrm{T}_{\mathrm{e} 1}$ and $\mathrm{T}_{\mathrm{e} 2}$ were used to obtain the 
average temperature of the evaporator section, while $T_{c 1}$ to $T_{c 5}$ were used to for the average temperature of the condenser section.

The geometry was constructed and meshed using the GAMBIT grid generation software. The solid and fluid regions contain 24,944 and 105,000 Quad cells, respectively. Near the left and right walls, fifteen layers of cells are used in order to capture the thin liquid film that develops in that region. The first grid size is $0.01 \mathrm{~mm}$ and the growth ratio is 1.2. Three layers of 180 cells have been used for the upper and bottom walls. Boundary conditions on the upper and lower caps of the thermosyphon are set to adiabatic, as shown in Figure 2.

Different mesh sizes were used to test grid independence as shown in Figure 3. The average temperature of the evaporator $\left(T_{\text {evaporator }}\right)$, adiabatic $\left(T_{\text {adiabatic }}\right)$ and condenser ( $T_{\text {condenser }}$ ) sections for different mesh sizes for the R134a working fluid were monitored and are shown in Table 1. For the R134a-charged thermosyphon and heating power of $30 \mathrm{~W}$, it was found that almost the same average temperatures for the evaporator, adiabatic and condenser sections were obtained for different mesh sizes. As a result, the mesh size of 129,944 Quad cells, Map cells is selected for the simulation analysis.

\section{BOUNDARY AND OPERATING CONDITIONS}

A non-slip boundary condition was imposed at the inner walls of the thermosyphon. In order to simulate the heating and evaporation, a constant heat flux was defined at the wall boundaries of the evaporator section, depending on the power input. A zero heat flux is defined as boundary condition on the adiabatic section. The condenser section was cooled as a result of heat released when vapour condenses. It has been assumed that the condenser is cooled by water, according to the experimental apparatus. Thus, a convection heat transfer coefficient was defined as boundary condition on the condenser's wall. The corresponding heat transfer coefficients have been calculated using the formula:

$$
h_{c}=\frac{Q_{c}}{2 \pi r L_{c}\left(T_{c, a v}-T_{\infty}\right)}
$$


where $h_{c}$ is the condenser heat transfer coefficient, $Q_{c}$ is the rate of heat transfer from the condenser, $L_{c}$ is the condenser height, $r$ is the pipe radius, $T_{c, a v}$ is the condenser average temperature and $T_{\infty}$ is the average temperature of the condenser cooling water. Figure 4 illustrates the boundary conditions implemented to the computational model.

In order to verify the sensitivity of the results to the value of the heat transfer coefficients, an empirical correlation proposed by Zukauskas [23] is used to determine the average Nusselt number for external forced convection over a circular pipe, defined as:

$$
\begin{gathered}
N u_{\text {Zukauskas }}=\frac{h_{c} \times D_{c}}{k_{l}}=0.683 \operatorname{Re}^{0.466} \operatorname{Pr}_{l}^{\frac{1}{3}} \quad(\text { for } 40 \leq \operatorname{Re} \geq 4000) \\
\operatorname{Re}=\frac{U x D_{c}}{v_{l}}
\end{gathered}
$$

where $k_{l}, v_{l}$ and $P r_{l}$ are the thermal conductivity, kinematic viscosity and Prandtl number of the condenser cooling water, $U$ is the inlet cooling water velocity and $D_{c}$ is the condenser outer diameter.

Churchill and Bernstein [24] reported an additional correlation to determine the average Nusselt number, defined as:

$$
N u_{\text {Churchill }}=\frac{h_{c} \times D_{c}}{k_{l}}=0.3+\frac{\operatorname{Re}^{0.5} \operatorname{Pr}^{\frac{1}{3}}}{\left[1+\left(0.4 / P_{r}\right)^{\frac{2}{3}}\right]^{\frac{1}{4}}}\left[1+\left(\frac{R e}{282,000}\right)^{\frac{5}{8}}\right]^{\frac{4}{5}}(0.62)
$$

In order to test the simulation results independence on the condenser heat transfer coefficients, correlations (7), (8) and (10) were checked for the heating power throughput of $30 \mathrm{~W}$ for the working fluid R134a. Thus, the average temperature of the evaporator, adiabatic and condenser sections are shown in Table 2. From this observation, it is apparent that the average temperature for the evaporator, adiabatic and condenser are very close for different tested correlations. Consequently, correlation (7) is selected to determine the heat transfer coefficients of the condenser's wall based on the experimental data (see Table 3). 
The model considered R134a or R404 as working fluids with a 100\% filling ratio of the evaporator section (i.e. $\mathrm{FR}=100 \%$ ). Apart from the density of the liquid phase and surface tension, the physical properties of the working fluids are assumed to be temperature-independent to limit the calculation time. These properties are taken at 298.15 K using the NIST REFPROP program [25], and can be found in Table 4.

The density of the liquid phase $\left(\rho_{l}\right)$ of the working fluid is considered as temperaturedependent and fitted into functions of temperature in the form of a high-order polynomial, defined as:

$$
\rho_{l}(T)=\sum_{i=0}^{n=4} C_{i} \cdot T^{i}
$$

where $C_{i}$ are the density coefficients listed in Table 5.

The effect of surface tension $\left(\sigma_{l v}\right)$ along the interface between the two phases is also considered as temperature-dependent and included in the model by using the following correlation.

$$
\sigma_{l v}(T)=\sum_{i=0}^{n=3} B_{i} \cdot T^{i}
$$

where $B_{i}$ are the surface tension coefficients listed in Table 5 .

The thermophysical properties listed in tables $4 \& 5$ have been obtained from the NIST REFPROP program [25].

\section{CFD SOLUTION PROCEDURE}

A transient simulation with a time step of $0.001 \mathrm{~s}$ is carried out to model the dynamic behaviour of the two-phase flow. The time step has been selected based on the Courant number, which is the ratio of the time step to the time a fluid takes to move across a cell. For VOF models, the maximum Courant number allowed near the interface is 250 [21]. For a time step of 0.001 , the Courant number is less than 1 . The simulation reaches a steady state within 120 s. 
FLUENT provides different segregated algorithms for pressure-velocity coupling. For reduced CPU time and to avoid convergence difficulties, a combination of the SIMPLE algorithm for pressure-velocity coupling and a first-order upwind scheme for the determination of momentum and energy is included in the model. GeoReconstruct and PRESTO discretization for the volume fraction and pressure interpolation scheme, respectively, are also performed in the simulation. In the current work, the numerical computation is considered to have converged when the scaled residual was $10^{-5}$ for the mass and velocity components and about $10^{-6}$ for the energy component.

The vapour phase of the working fluid is defined as the primary phase and the liquid phase is defined as the secondary phase. For the calculation of the mass and heat transfer during the evaporation and condensation processes, the boiling temperatures and the latent heat of evaporation of the working fluids have been defined in the UDF code. When the simulation was started, the liquid pool in the evaporator is heated first. Once the saturation temperature defined in the UDF is reached, evaporation starts and phase change occurs due to boiling at the inner evaporator wall. The saturated vapour then flows upward, where it condenses along the inner cold walls of the condenser forming a thin liquid film.

\section{FLOW VISUALISATION OF CFD SIMULATION}

In the following sub-sections, the CFD simulation findings from the tests will be visualised and an analysis of the nature of the heat transfer, pool boiling and liquid film condensation processes within the R134a and R404a charged thermosyphons will be discussed.

\subsection{Heat transfer process}

In order to understand the heat transfer process during the thermosyphon operation, the temperature contours at different times have been observed during the start-up (heating) and steady-state operation. In this visual observation, the temperature distribution in the fluid region inside the evaporator, adiabatic and condenser sections has been recorded for both R134a and R404a. The results for R134a are shown in 
Figure 5. A heating power of $30 \mathrm{~W}$ was selected to compare the heat transfer process for both working fluids.

At the beginning of the heating procedure, the operating pressure and temperature of the working fluid were set to the saturation values at the initial temperature of the heat pipe (around $25^{\circ} \mathrm{C}$ for both cases), as shown in Figure 5. Between $2.0 \mathrm{~s}$ and 8.0 $\mathrm{s}$, the temperature in the evaporator increases as a constant heat is applied to the outer wall of the evaporator section, which allows heat to transfer through the evaporator wall into the liquid pool, as shown in Figure 5. Boiling heat transfer continues on the walls of the evaporator section due to the temperature difference between the wall and the saturated working fluid within the thermosyphon. The generated vapour then moves upward, as shown at $20 \mathrm{~s}$, and this vapour flows through the adiabatic section to the condenser section, as can be seen at $30 \mathrm{~s}, 40 \mathrm{~s}$ and $50 \mathrm{~s}$ in Figure 5. Then, a high temperature region appears in the condenser section between $60 \mathrm{~s}$ and $90 \mathrm{~s}$ due to the vapour reaching this section. The region near the inner wall of the condenser section has a lower temperature than the middle region as a result of vapour condensing along the inner surface of the condenser wall. Eventually, between $100 \mathrm{~s}$ and $120 \mathrm{~s}$, the temperature distribution inside the thermosyphon becomes uniform as shown in Figure 5. The above described procedure shows the heat transfer process during the operation of the thermosyphon charged with R134a. The same can be observed for the case when the thermosyphon was charged with R404a. Consequently, the temperature distribution in the fluid region inside the thermosyphon for R404a has not been shown.

\subsection{Evaporation process}

The pool boiling phenomena taking place inside the evaporator section has also been visualised during the evaporation process. Figure 6 shows the volume fraction contours of the liquid pool in the evaporator section for R134a, for a power throughput of $30 \mathrm{~W}$. The liquid pool of the tested working fluid is represented by a blue colour, which takes the value of 0 for the vapour volume fraction, and the vapour is represented by a red colour, which takes the value of 1 for the vapour volume fraction. 
The working fluids have initially filled the total volume of the evaporator section, as shown in Figure 6 at 0.0 s. By applying a constant heat flux onto the wall of the evaporator section, heat is then conducted through the evaporator wall to the inner wall to be transferred into the saturated liquid by boiling. Due to the weight of the working fluid column, localised natural convection currents at the lower half of the evaporator section can be seen due to the slight increase in the saturation pressure/temperature of the working fluid. The liquid starts to boil at a position where the liquid temperature at the wall exceeds the saturation temperature (at the adjacent liquid film that is stuck on the inner wall of the evaporator), hence local nucleation sites critical radiuses are exceeded so continuous nucleation takes place. Vapour bubbles then start to form at those positions, as shown in Figure 6 between $2.0 \mathrm{~s}$ and $10 \mathrm{~s}$. By continuous nucleation, isolated vapour bubbles form and rise all the way up to the top region of the liquid pool before breaking up and releasing their vapour content. This is illustrated in Figure 6 at time $20 \mathrm{~s}$ and above. During the evaporation process described above, the liquid volume fraction decreases and the vapour volume fraction increases. The same procedure has been obtained for R404a. Consequently, the volume fraction contours of the liquid pool in the evaporator section for R404a have not been shown.

It is clear from Figure 6 that the pool boiling behaviour of R134a is significantly different to that of water, as very small bubbles grow during the pool boiling. The reason behind this is related to the value of the critical nucleation site radiuses. Fadhl et al [1] reported CFD simulations of the pool boiling behaviour of water with the filling ratio of $50 \%$, a snapshot of which can be seen in Figure 7 . The results for both water and the refrigerants have been validated visually using transparent glass wickless heat pipes. This provides evidence that the CFD model has the ability to reproduce the difference in pool boiling behaviour between different working fluids.

\subsection{Condensation process}

Following the boiling process, the converse process takes place in the condenser section. The CFD model predicts the condensate film configuration as illustrated in 
Figure 8 for the R404a charged thermosyphon that was undergoing a power throughput of $30 \mathrm{~W}$.

It is illustrated that the liquid film will then fall down under gravity through the adiabatic section, which is clearly shown in Figure 8 at the adiabatic zone. Eventually, the liquid pool in the evaporator section will be charged by a continuous thin liquid film as illustrated in Figure 8 at the evaporator zone.

\section{TEMPERATURE DISTRIBUTION OF CFD SIMULATION OF THERMOSYPHON}

The temperature profiles along the modelled thermosyphon have been observed under different power throughputs using 8 positions in the model, which allowed the monitoring of the average wall temperatures of the evaporator, adiabatic and condenser sections. Two positions placed $40 \mathrm{~mm}$ and $160 \mathrm{~mm}$ from the bottom are used to monitor the evaporator section and one position is used at the centre of the adiabatic section. Five evenly spaced positions are used to monitor the condenser section. These five positions are used to confirm the absence of non-condensable gases which, if present, would be swept by the vapour towards the top area of the condenser section where they would accumulate and reduce the thermal performance. Thus, non-condensable gases are neglected in the current CFD model.

Figures 9 and 10 illustrate the experimental and CFD simulation temperature distributions along the R134a and R404a charged thermosyphons, respectively, for varying applied heat loads. The distance between 0 and $200 \mathrm{~mm}$ indicates the evaporator section, while the distance between 300 and $500 \mathrm{~mm}$ indicates the condenser section. The middle section is the adiabatic region. The CFD simulation results of temperature distribution profiles have been compared with the experimental data by determining the average relative error (ARE), which is the absolute percentage difference between CFD simulation and experimental average wall temperature. As depicted in Figures 9 and 10, the CFD simulation results showed the same trend as the experimental results. 
Referring to Figures 9 and 10, the CFD simulation results of the selected thermosyphon showed very good agreement with the temperature profiles from experimental data for the lower power throughputs. The average wall temperatures of the evaporator, adiabatic and condenser are close to those obtained in the experiments. As a result, the ARE of evaporator, adiabatic and condenser average wall temperatures are $1.25 \%, 0.78 \%$ and $1.03 \%$, respectively for R134a, and 2.66\%, $0.78 \%$ and $0.49 \%$, respectively for R404a. For heat loads above approximately $60 \mathrm{~W}$, the predicted CFD evaporator average temperature has deviated from the experimental results due to the consideration of a continuous heat power input along the length of the evaporator section where, in the experiment, a wire heater is evenly wrapped around the evaporator section to ensure it was not directly above a thermocouple.

\section{CONCLUSIONS}

A two-phase closed thermosyphon is considered in this paper when charged with two working fluids, R134a and R404a, in CFD simulations of the evaporation and condensation phenomena inside the thermosyphon. The findings of the CFD simulations demonstrate that the proposed CFD model can successfully reproduce the complex phenomena inside the thermosyphon, including the pool boiling in the evaporator section and the liquid film in the condenser section. The proposed CFD model was validated solely with the limited experimental data available and further validation is still necessary over greater operating ranges/configurations.

The CFD results show that the pool boiling behaviour of both refrigerants is significantly different to that of water, as very small bubbles grow during the pool boiling. The results for both water and the refrigerants have been validated by visualisation experiments carried out with a transparent glass heat pipe. This provides evidence that the CFD model has the ability to simulate thermosyphons charged with different working fluids. 
The average wall temperature along the thermosyphon has been compared with the experimental results at the same condition for both working fluids, and demonstrates that the predicted CFD simulation results agreed with the experimental results.

\section{Acknowledgment}

The first author deeply appreciates the financial support in the form of a $\mathrm{PhD}$ studentship offered by Mechanical Engineering Department, Umm Al-Qura University, Ministry of Higher Education, Kingdom of Saudi Arabia.

\section{REFERENCES}

[1] Fadhl B, Wrobel LC, Jouhara H. Numerical modelling of the temperature distribution in a two-phase closed thermosyphon. Applied Thermal Engineering 2013; 60: 122-131.

[2] Kerrigan K, Jouhara H, O'Donnell GE, Robinson AJ. Heat pipe-based radiator for low grade geothermal energy conversion in domestic space heating. Simulation Modelling Practice and Theory 2011; 19: 1154-1163.

[3] ESDU. Heat pipes - general information on their use, operation and design. ESDU Manual 800131980.

[4] Faghri A. Heat Pipe Science and Technology. Taylor \& Francis: Washington, D.C., 1995.

[5] Dunn P, Reay DA. Heat Pipes. Pergamon Press: New York, 1994;343.

[6] Jouhara H, Meskimmon R. Experimental investigation of wraparound loop heat pipe heat exchanger used in energy efficient air handling units. Energy 2010; 35: 4592-4599.

[7] Mathioulakis E, Belessiotis V. A new heat-pipe type solar domestic hot water system. Solar Energy 2002; 72: 13-20.

[8] Weng Y-, Cho H-, Chang C-, Chen S-. Heat pipe with PCM for electronic cooling. Applied Energy 2011; 88: 1825-1833.

[9] Reay D, Kew P. Heat Pipes: Theory, Design and Applications. Elsevier Science \& Technology: UK, 2009;367. 
[10] Jouhara H, Robinson AJ. An experimental study of small-diameter wickless heat pipes operating in the temperature range $200^{\circ} \mathrm{C}$ to $450^{\circ} \mathrm{C}$. Heat Transfer Engineering 2009; 30: 1041-1048.

[11] Groll M. Heat pipe research and development in western Europe. Heat Recovery Systems and CHP 1989; 9: 19-66.

[12] Abou-Ziyan HZ, Helali A, Fatouh M, Abo El-Nasr MM. Performance of stationary and vibrated thermosyphon working with water and R134a. Applied Thermal Engineering 2001; 21: 813-830.

[13] Ong KS, Haider-E-Alahi M. Performance of a R-134a-filled thermosyphon. Applied Thermal Engineering 2003; 23: 2373-2381.

[14] Yau YH, Foo YC. Comparative study on evaporator heat transfer characteristics of revolving heat pipes filled with R134a, R22 and R410A. International Communications in Heat and Mass Transfer 2011; 38: 202-211.

[15] Jiao B, Qiu LM, Zhang XB, Zhang Y. Investigation on the effect of filling ratio on the steady-state heat transfer performance of a vertical two-phase closed thermosyphon. Applied Thermal Engineering 2008; 28: 1417-1426.

[16] Kafeel K, Turan A. Simulation of the response of a thermosyphon under pulsed heat input conditions. International Journal of Thermal Sciences 2014; 80: 3340 .

[17] Amatachaya P, Srimuang W. Comparative heat transfer characteristics of a flat two-phase closed thermosyphon (FTPCT) and a conventional two-phase closed thermosyphon (CTPCT). International Communications in Heat and Mass Transfer 2010; 37: 293-298.

[18] Alizadehdakhel A, Rahimi M, Alsairafi AA. CFD modeling of flow and heat transfer in a thermosyphon. International Communications in Heat and Mass Transfer 2010; 37: 312-318.

[19] Zhang M, Liu Z, Ma G, Cheng S. Numerical simulation and experimental verification of a flat two-phase thermosyphon. Energy Conversion and Management 2009; 50: 1095-1100.

[20] Annamalai AS, Ramalingam V. Experimental investigation and computational fluid dynamics analysis of an air cooled condenser heat pipe. Thermal Science 2011; 15: 759-772.

[21] Lin Z, Wang S, Shirakashi R, Winston Zhang L. Simulation of a miniature oscillating heat pipe in bottom heating mode using CFD with unsteady modeling. International Journal of Heat and Mass Transfer 2013; 57: 642-656. 
[22] De Schepper SCK, Heynderickx GJ, Marin GB. Modeling the evaporation of a hydrocarbon feedstock in the convection section of a steam cracker. Computers \& Chemical Engineering 2009; 33: 122-132.

[23] Žukauskas A. Heat Transfer from Tubes in Crossflow. Advances in Heat Transfer. Elsevier:93-160.

[24] Churchill SW, Bernstein M. Correlating equation for forced convection from gases and liquids to a circular cylinder in crossflow. Journal of Heat Transfer 1977; 99: 300-306.

[25] Lemmon EW, Huber ML, McLinden MD. NIST Standard Reference Database 23: Reference Fluid Thermodynamics and Transport Properties-REFPROP. National Institute of Standards and Technology, Standard Reference Data Program, Gaithersburg 2013; Version 9.1. 


\section{TABLES}

Table 1: Grid-independence results for thermosyphon charged with R134a

\begin{tabular}{|l|c|c|c|c|}
\hline \multicolumn{2}{|l|}{ Mesh size (cells) } & 19,500 & 69,276 & 129,944 \\
\hline $\mathrm{T}_{\text {evaporator }}$ & $\mathrm{K}$ & 303.66 & 302.31 & 302.47 \\
\hline $\mathrm{T}_{\text {adiabatic }}$ & $\mathrm{K}$ & 299.18 & 299.01 & 299.64 \\
\hline $\mathrm{T}_{\text {condenser }}$ & $\mathrm{K}$ & 294.63 & 294.80 & 295.62 \\
\hline
\end{tabular}

Table 2: Average temperatures for the thermosyphon charged with R134a for different heat transfer coefficient correlations

\begin{tabular}{|l|c|c|c|c|}
\hline $\begin{array}{l}\text { Correlation of condenser } \\
\text { heat transfer coefficient }\end{array}$ & Eq. (7) & Eq. (8) & Eq. (10) \\
\hline $\mathrm{h}_{\mathrm{c}}$ & $\mathrm{W} / \mathrm{m}^{2} . \mathrm{K}$ & 394.4 & 592.3 & 654.6 \\
\hline $\mathrm{T}_{\text {evaporator }}$ & $\mathrm{K}$ & 302.47 & 302.29 & 302.22 \\
\hline $\mathrm{T}_{\text {adiabatic }}$ & $\mathrm{K}$ & 299.64 & 299.80 & 299.74 \\
\hline $\mathrm{T}_{\text {condenser }}$ & $\mathrm{K}$ & 295.62 & 295.14 & 294.99 \\
\hline
\end{tabular}

Table 3: Condenser heat transfer coefficients for different heat inputs

\begin{tabular}{|c|c|c|c|c|}
\hline \multicolumn{5}{|c|}{ R134a } \\
\hline Evaporator & Condenser cooling & \multicolumn{3}{|c|}{ Condenser section } \\
\hline$Q_{\text {in }}$ & $\mathrm{T}_{\infty}$ & $\mathrm{Q}_{\mathrm{c}}$ & $\mathrm{T}_{\mathrm{c} \text { av }}$ & $\mathrm{h}_{\mathrm{c}}$ \\
\hline $\mathrm{W}$ & $\mathrm{K}$ & $\mathrm{W}$ & $\mathrm{K}$ & $\mathrm{W} / \mathrm{m}^{2} \cdot \mathrm{K}$ \\
\hline 19.74 & 293.4 & 19.74 & 296.1 & 531.6 \\
\hline 29.58 & 292.2 & 29.58 & 297.6 & 394.4 \\
\hline 39.53 & 291.4 & 39.53 & 301.5 & 284.6 \\
\hline 50.16 & 292.1 & 50.16 & 300.8 & 414.6 \\
\hline 100.44 & 296.7 & 100.44 & 306.7 & 728.4 \\
\hline \multicolumn{5}{|c|}{ R404a } \\
\hline 19.88 & 298.3 & 19.88 & 300.3 & 730.3 \\
\hline 29.04 & 296.3 & 29.04 & 298.7 & 848.7 \\
\hline 40.66 & 296.1 & 40.66 & 299.4 & 894.7 \\
\hline 49.61 & 296.9 & 49.61 & 301 & 885.5 \\
\hline 100.65 & 297.3 & 100.65 & 304.5 & 1008.7 \\
\hline
\end{tabular}


Table 4: Physical properties of the working fluids [25]

\begin{tabular}{|l|c|c|c|}
\hline \multirow{2}{*}{ Physical property } & \multirow{2}{*}{ Units } & \multicolumn{2}{c|}{ Working fluid } \\
\cline { 3 - 4 } & & $\mathrm{R} 134 \mathrm{a}$ & $\mathrm{R} 404 \mathrm{a}$ \\
\hline Latent heat of evaporation & $\mathrm{kJ} / \mathrm{kg}$ & 177.79 & 140.25 \\
\hline Density of vapour phase & $\mathrm{kg} / \mathrm{m}^{3}$ & 32.35 & 65.247 \\
\hline Specific heat of liquid phase & $\mathrm{kJ} / \mathrm{kg} . \mathrm{K}$ & 1.4246 & 1.5423 \\
\hline Specific heat of vapour phase & $\mathrm{kJ} / \mathrm{kg} . \mathrm{K}$ & 1.0316 & 1.2214 \\
\hline $\begin{array}{l}\text { Thermal conductivity of liquid } \\
\text { phase }\end{array}$ & $\mathrm{W} / \mathrm{m} . \mathrm{K}$ & 0.081134 & 0.063625 \\
\hline $\begin{array}{l}\text { Thermal conductivity of vapour } \\
\text { phase }\end{array}$ & $\mathrm{W} / \mathrm{m} . \mathrm{K}$ & 0.013825 & 0.015905 \\
\hline Viscosity of liquid phase & $\mathrm{kg} / \mathrm{m} . \mathrm{s}$ & $1.9489 \times 10^{-04}$ & $1.2827 \times 10^{-04}$ \\
\hline Viscosity of vapour phase & $\mathrm{kg} / \mathrm{m} . \mathrm{s}$ & $1.1693 \times 10^{-05}$ & $1.2152 \times 10^{-05}$ \\
\hline Molecular weight & $\mathrm{kg} / \mathrm{kmol}$ & 102.03 & 97.604 \\
\hline Critical temperature & $\mathrm{K}$ & 374.21 & 345.27 \\
\hline Critical pressure & $\mathrm{kPa}$ & 40593 & 3734.9 \\
\hline
\end{tabular}

Table 5: Density and surface tension coefficients of the working fluids

\begin{tabular}{|c|c|c|c|c|c|}
\hline \multirow{2}{*}{$\begin{array}{c}\text { Working } \\
\text { fluid }\end{array}$} & \multicolumn{5}{|c|}{ Density $\rho_{l}$} \\
\cline { 2 - 6 } & $\mathrm{C}_{0}$ & $\mathrm{C}_{1}$ & $\mathrm{C}_{2}$ & $\mathrm{C}_{3}$ & $\mathrm{C}_{4}$ \\
\hline $\mathrm{R} 134 \mathrm{a}$ & 3952.801 & -25.9914 & 0.09482 & $-1.290 \times 10^{-04}$ & 0 \\
\hline $\mathrm{R} 404 \mathrm{a}$ & -23723.15 & 380.3528 & -2.14135 & 0.005318 & $-4.965 \times 10^{-06}$ \\
\hline & \multicolumn{5}{|c|}{ Surface tension $\sigma_{l v}$} \\
\hline & $\mathrm{B}_{0}$ & $\mathrm{~B}_{1}$ & $\mathrm{~B}_{2}$ & $\mathrm{~B}_{3}$ & - \\
\hline $\mathrm{R} 134 \mathrm{a}$ & 0.04929 & $-8.34 \times 10^{-05}$ & $-3.95 \times 10^{-07}$ & $7.071 \times 10^{-10}$ & - \\
\hline $\mathrm{R} 404 \mathrm{a}$ & 0.03121 & $7.1086 \times 10^{-05}$ & $-9.82 \times 10^{-07}$ & $1.485 \times 10^{-09}$ & - \\
\hline
\end{tabular}




\section{FIGURES}

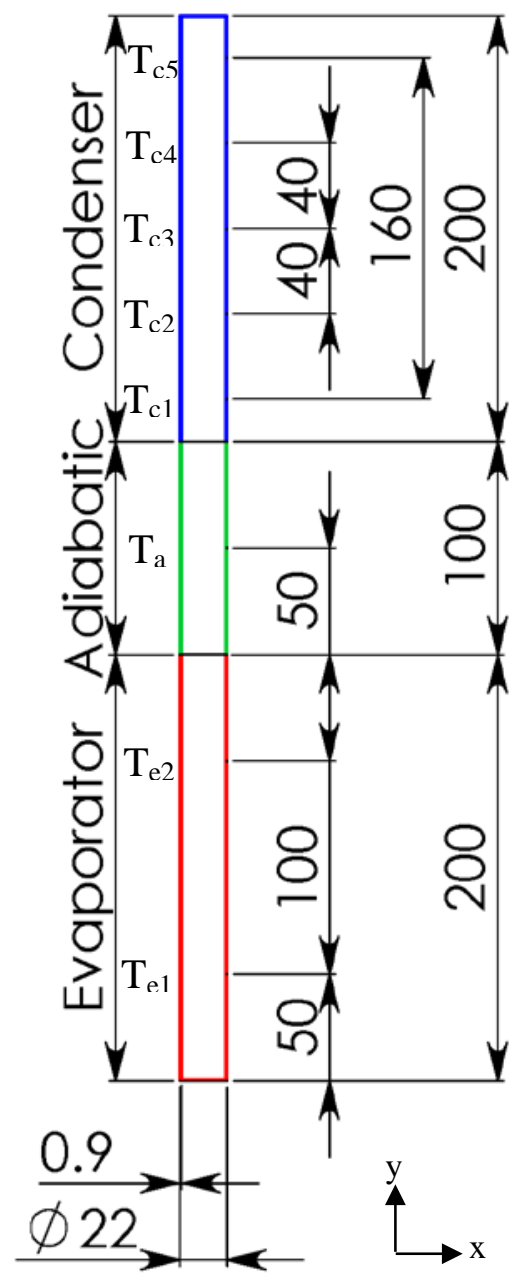

Figure 1: Model geometry and dimension [1] 


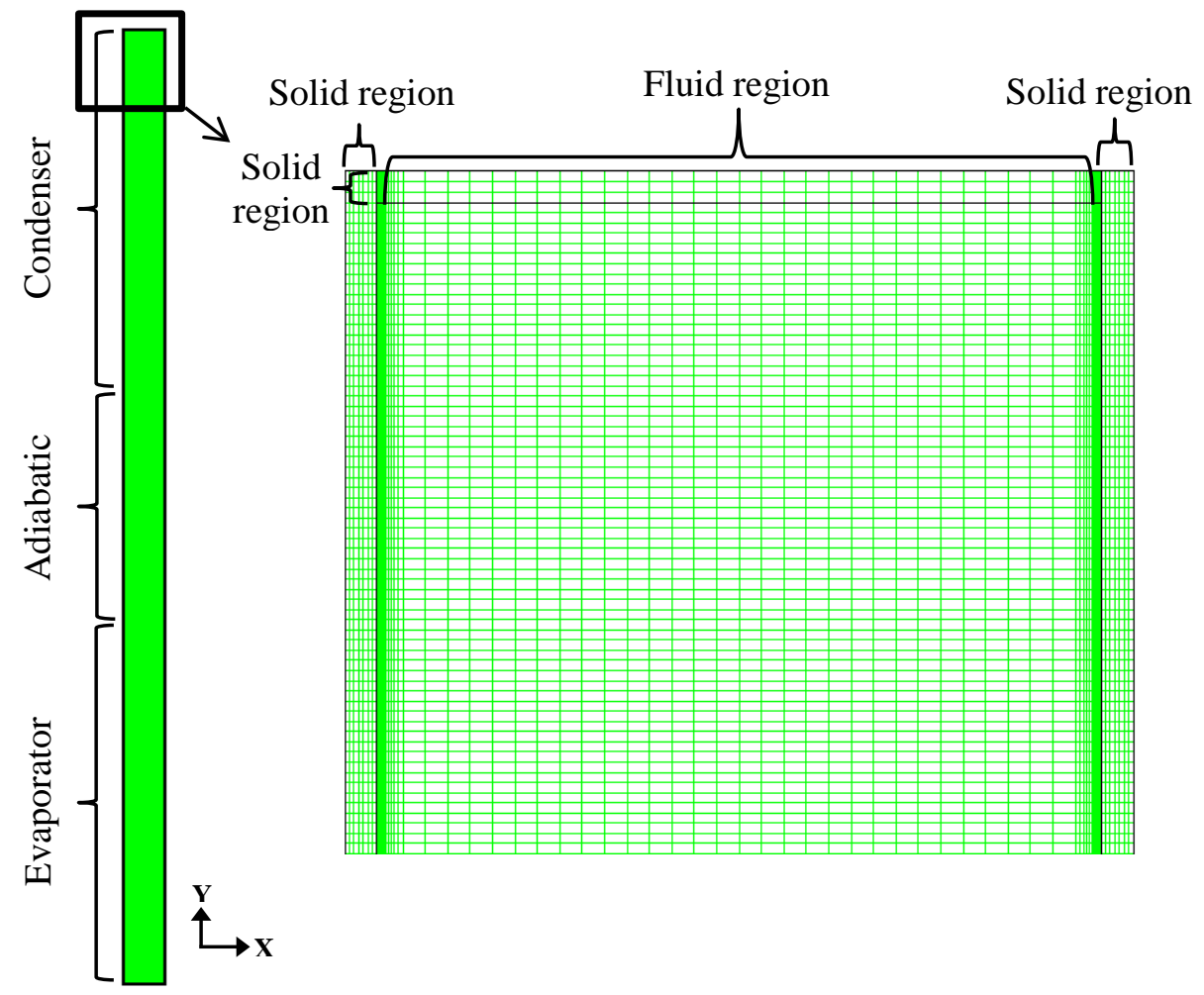

Figure 2: Mesh distribution

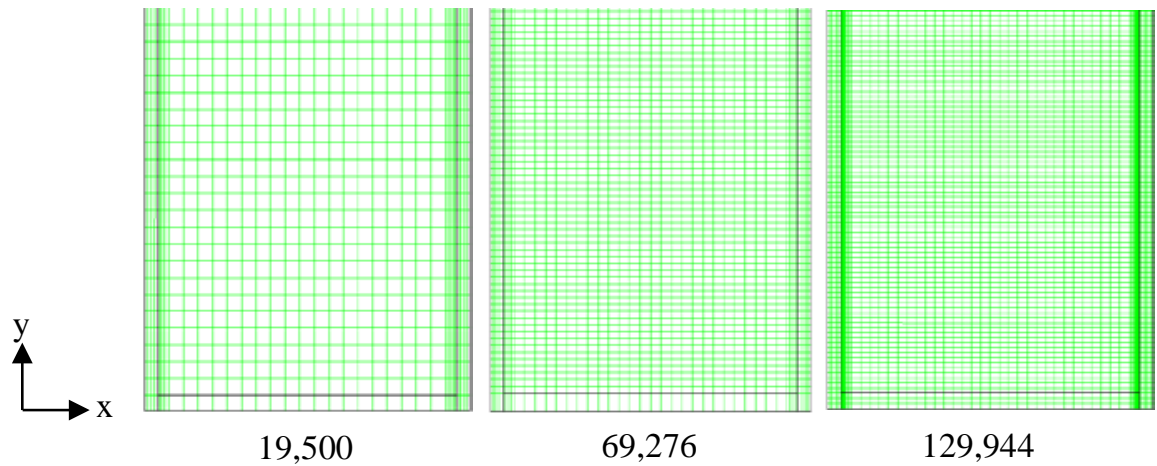

Figure 3: A section of the computational mesh 


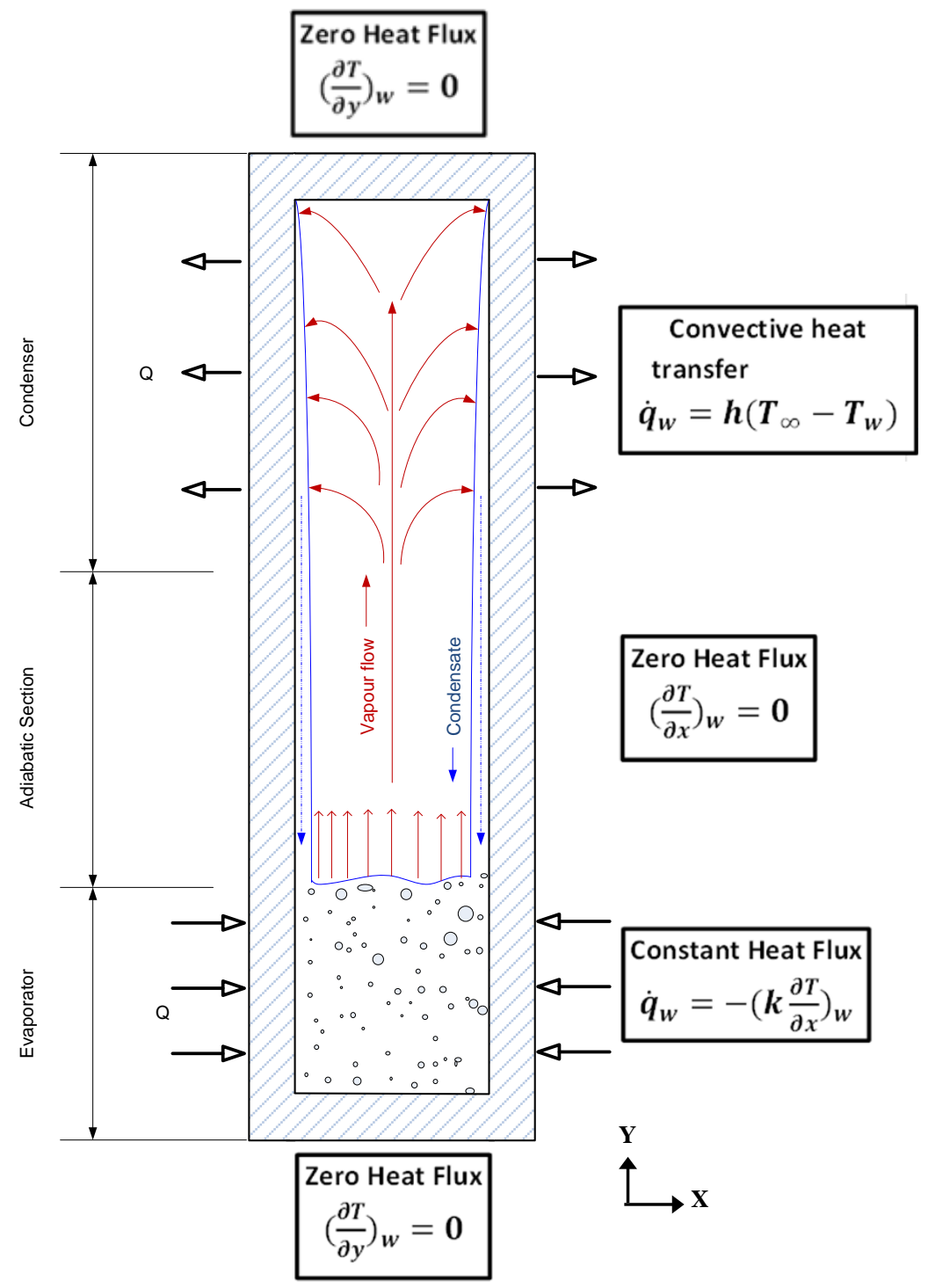

Figure 4: Boundary conditions of the CFD model 


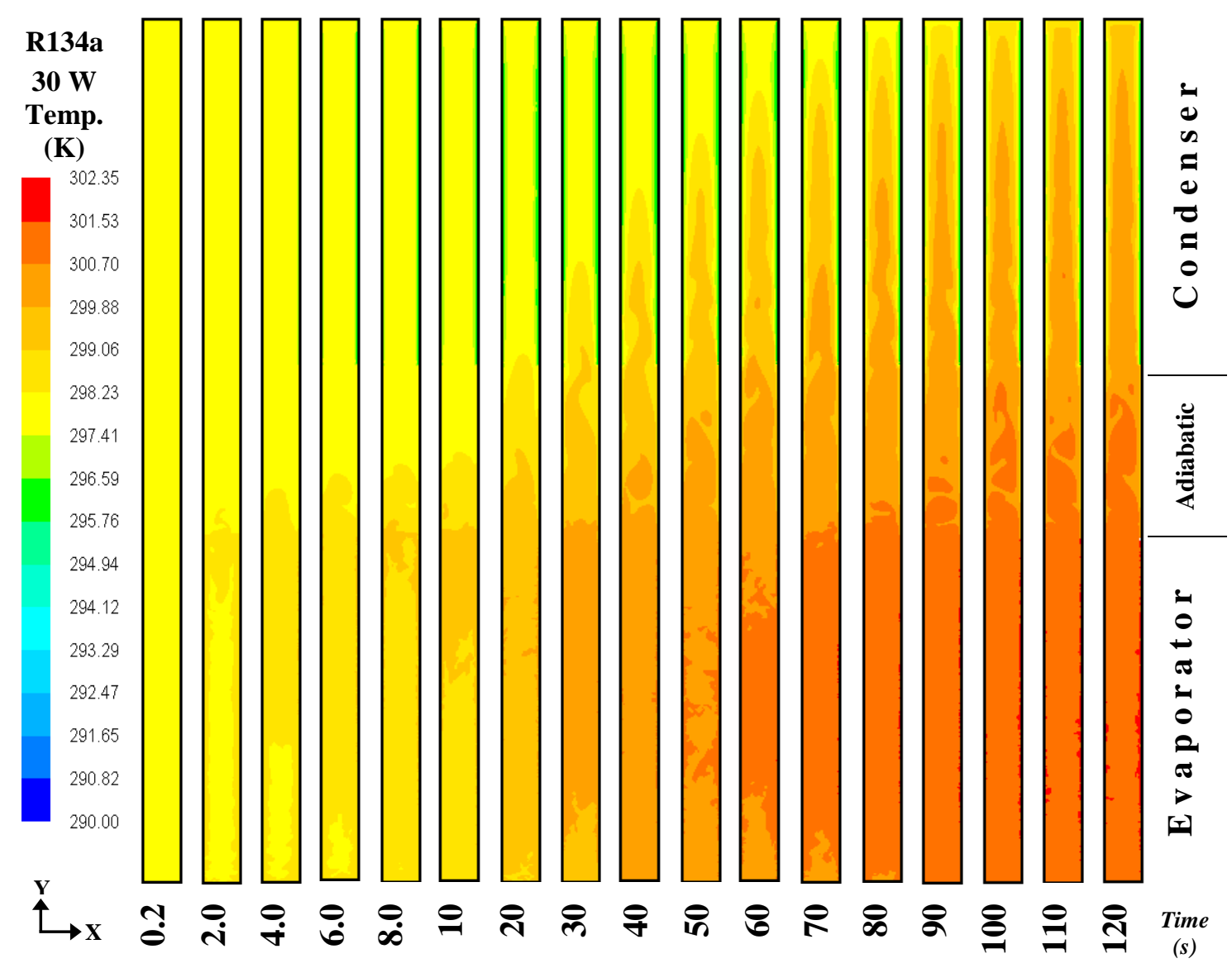

Figure 5: Heat transfer process for R134a-filled thermosyphon at different times 


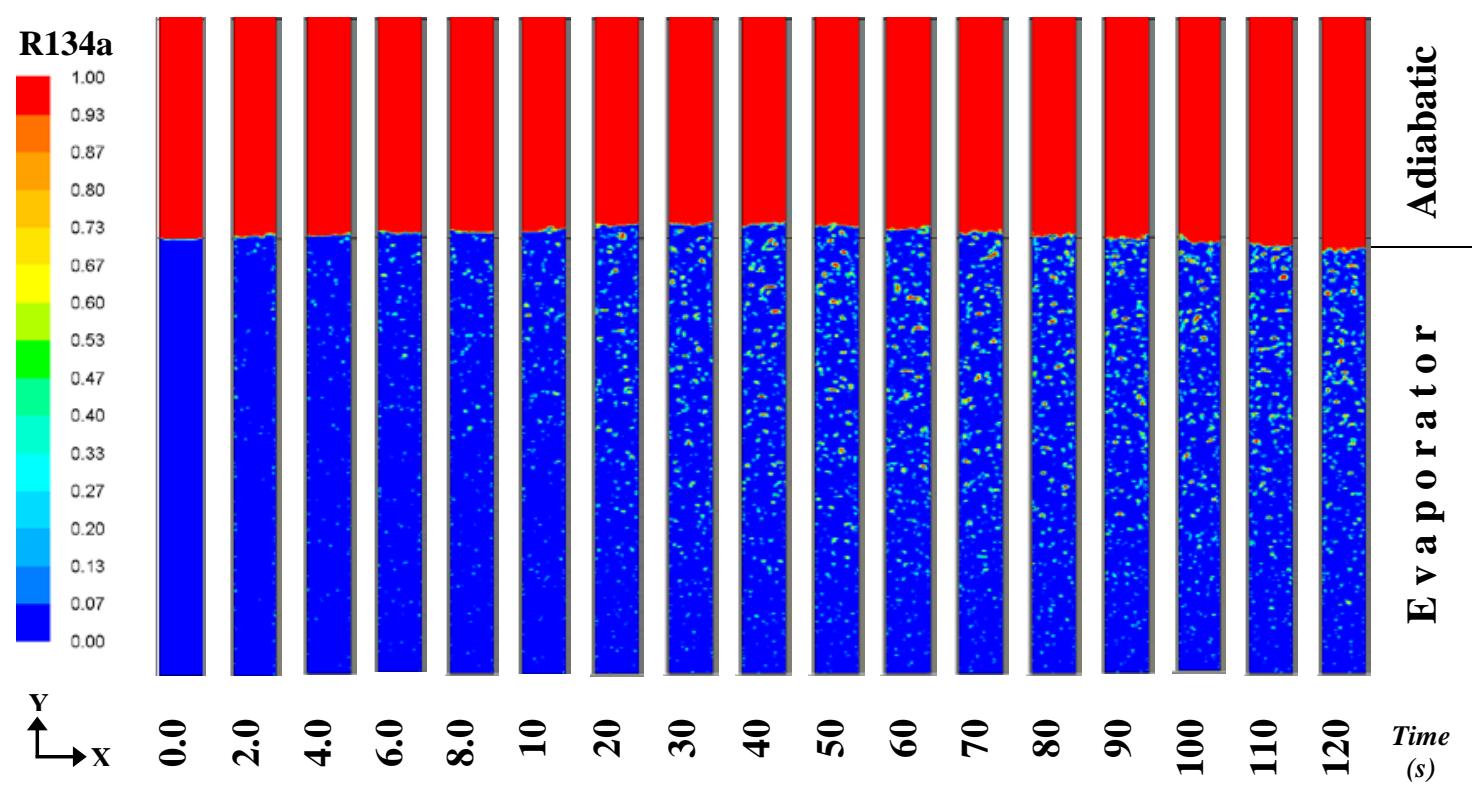

Figure 6: Pool boiling process in the evaporator section for R134a-filled thermosyphon

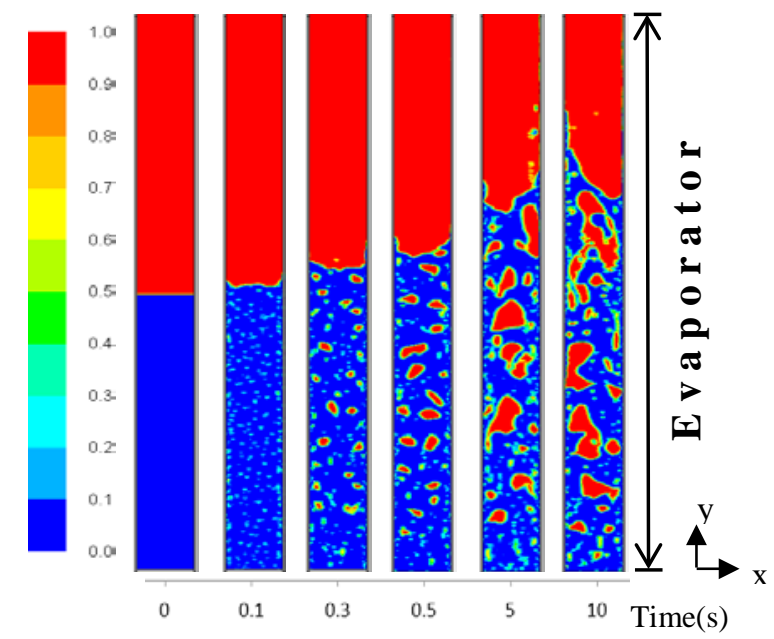

Figure 7: Pool boiling in the evaporator section for water-filled thermosyphon with filling ratio of $50 \%$ reported by Fadhl et al. [1] 


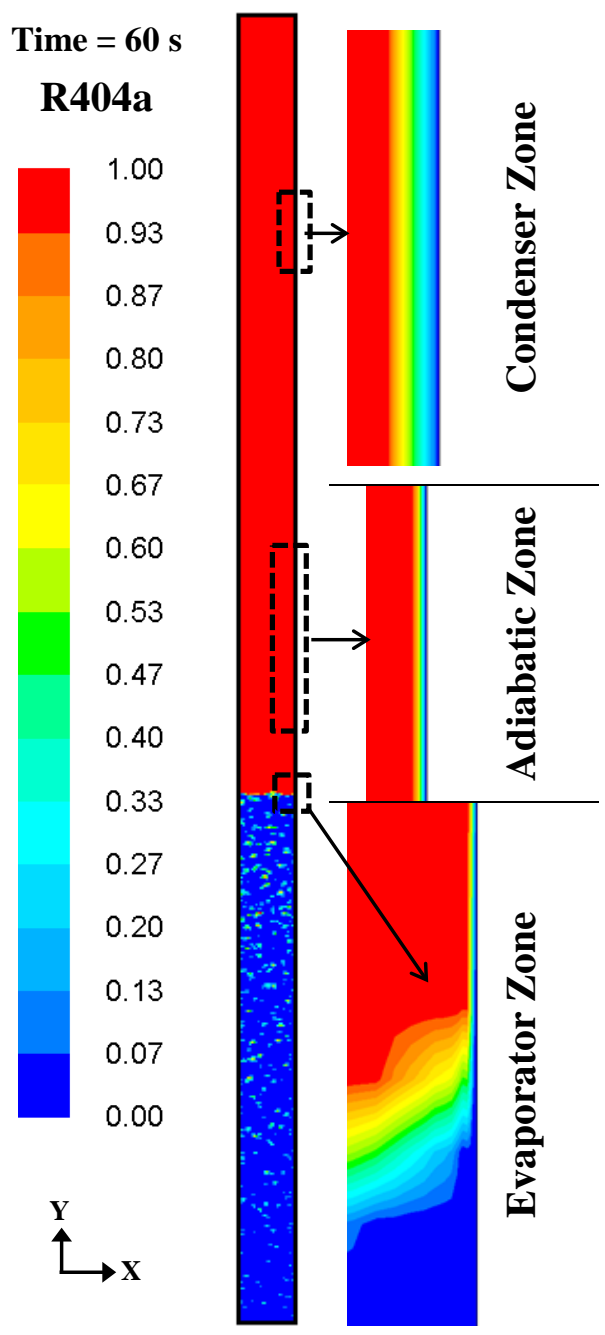

Figure 8: Liquid film condensation process for R404afilled thermosyphon 

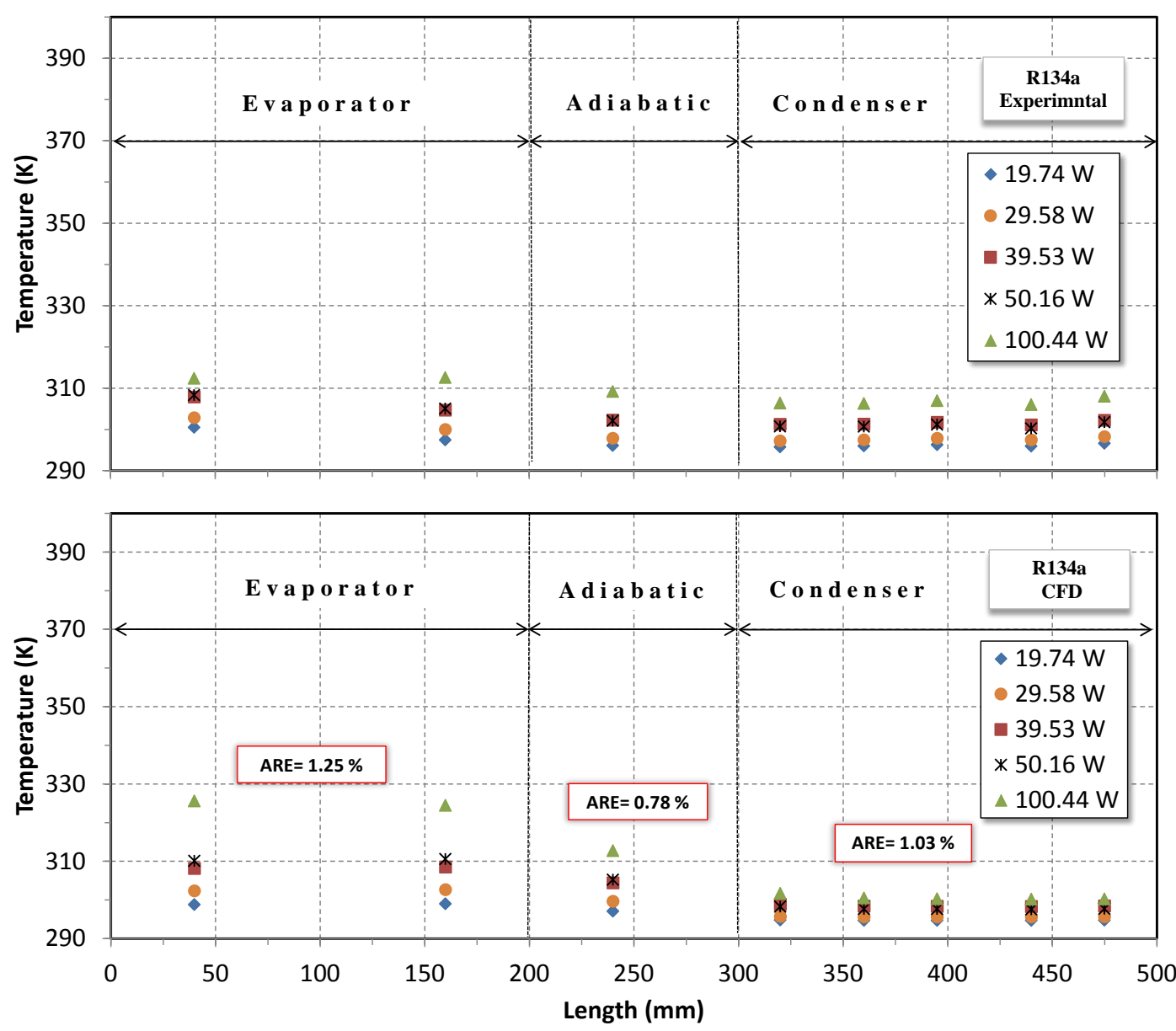

Figure 9: Temperature distribution profiles for experiments and CFD simulations along R134a-filled thermosyphon for different heat loads 


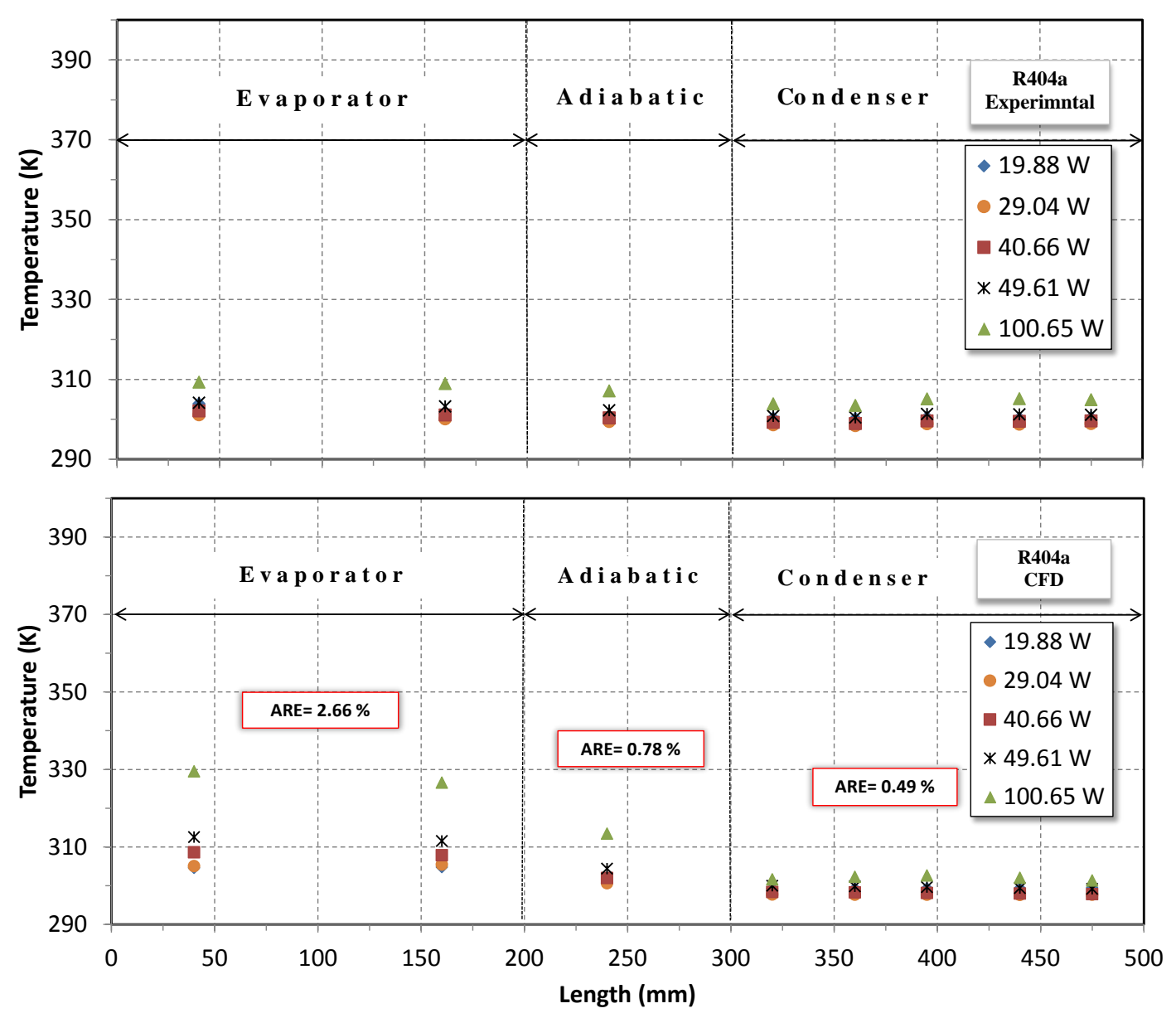

Figure 10: Temperature distribution profiles for experiments and CFD simulations along R404a-filled thermosyphon for different heat loads 